\title{
High-entropy alumino-silicides: a novel class of high-entropy ceramics
}

\author{
Tongqi Wen ${ }^{1,2 \dagger}$, Honghua Liu ${ }^{1 \dagger}$, Beilin $\mathrm{Ye}^{1}, \mathrm{Da} \mathrm{Liu}^{1}$ and Yanhui $\mathrm{Chu}^{1 *}$
}

\begin{abstract}
High-entropy ceramics (HECs) are gaining significant interest due to their huge composition space, unique microstructure, and adjustable properties. Previously reported studies focus mainly on HECs with the multi-cationic structure, while HECs with more than one anion are rarely studied. Herein we reported a new class of HECs, namely highentropy alumino-silicides $\left(\mathrm{Mo}_{0.25} \mathrm{Nb}_{0.25} \mathrm{Ta}_{0.25} \mathrm{~V}_{0.25}\right)\left(\mathrm{Al}_{0.5} \mathrm{Si}_{0.5}\right)_{2}$ (HEAS-1) with multi-cationic and -anionic structure. The formation possibility of HEAS-1 was first theoretically analyzed from the aspects of thermodynamics and lattice size difference based on the first-principles calculations and then the HEAS-1 were successfully synthesized by the solid-state reaction at $1573 \mathrm{~K}$. The as-synthesized HEAS-1 exhibited good single-crystal hexagonal structure of metal alumino-silicides and simultaneously possessed high compositional uniformity. This study not only enriches the categories of HECs but also will open up a new research field on HECs with multi-cationic and -anionic structure.
\end{abstract}

Keywords: high-entropy ceramics, alumino-silicides, first-principles calculations, solid solutions

\section{INTRODUCTION}

Since their discovery in 2004, high-entropy alloys (HEAs) have attracted significant research interest for their huge composition space, unique microstructure, adjustable properties, and various potential applications [1,2]. Generally, in a HEA, four or more principal elements can be mixed in near-equiatomic ratios or at least with each element being between 5 at $\%$ and 35 at $\%$ to generate a maximum molar configurational entropy of $\Delta S_{\text {mix }}=R \cdot \ln N$, where $N$ is the number of components and $R$ is the gas constant [1-3]. As a result, HEAs exhibit superior strength and ductility [4], outstanding irradiation resistance [5], good corrosion resistance [6], high fracture toughness [7], interesting creep characteristics [8] and plastic behavior [9]. Inspired by HEAs concept, the concept of high-entropy ceramics (HECs), namely multicomponent ionic compounds, was first proposed in the multicomponent metal oxides in 2015 [10] and then it has been gaining significant interest in recent years. Up to now, extensive efforts have been devoted to exploring the diverse HECs, including metal oxides $[10,11]$, carbides [12-16], diborides [17-19], and silicides [20,21], with wide-ranging applications in the structural and functional fields. These HECs show many superior mechanical, physical and chemical performances, such as high hardness and modulus, low thermal conductivity, good thermodynamics stability and corrosion resistance, superior electrochemical and physicochemical properties [1014,16,17,22,23]. Unlike HEAs, whose structures consist of a single lattice occupied by metal elements $[1,2]$, the structures of HECs involve a cationic sublattice and an anionic sublattice occupied by metal elements and nonmetallic element, respectively. Consequently, the disorder of the cationic and anionic sites for HECs can contribute to a maximum molar configurational entropy of $\Delta S_{\text {mix }}=$ $\Delta S_{\text {cation }}+\Delta S_{\text {anion }}$, where $\Delta S_{\text {cation }}$ and $\Delta S_{\text {anion }}$ are the entropy of cationic and anionic site contribution, respectively. As far as we are concerned, the previously reported studies focus mainly on HECs with the multi-cationic structure, while so far there are very few reports on HECs with more than one anion. In other words, only the cationic site contributes to $\Delta S_{\text {mix }}$ for the reported HECs since the contribution from the anionic site is zero. It is worth mentioning that a higher $\Delta S_{\text {mix }}$ is closely related to much more superior mechanical, physical and chemical properties, especially thermodynamics stability. Therefore, the exploration of new HECs with higher $\Delta S_{\text {mix }}$, namely with multi-cationic and -anionic structure, is of great interest

\footnotetext{
${ }^{1}$ School of Materials Science and Engineering, South China University of Technology, Guangzhou 510641, China

${ }^{2}$ School of Natural and Applied Sciences, Northwestern Polytechnical University, Xi'an 710072, China

${ }^{\dagger}$ These authors contributed equally to this work.

* Corresponding author (email: chuyh@scut.edu.cn)
} 
for the scientific community.

In this work, a new class of HECs, namely high-entropy alumino-silicides $\quad\left(\mathrm{Mo}_{0.25} \mathrm{Nb}_{0.25} \mathrm{Ta}_{0.25} \mathrm{~V}_{0.25}\right)\left(\mathrm{Al}_{0.5} \mathrm{Si}_{0.5}\right)_{2}$ (HEAS-1) with multi-cationic and -anionic structure, was reported for the first time. The formation possibility of HEAS- 1 was first analyzed from lattice size difference and thermodynamics based on the first-principles calculations and then the HEAS-1 was successfully synthesized by solid-state reaction at $1573 \mathrm{~K}$. In addition, the phase compositions, microstructure, and compositional uniformity of the as-synthesized HEAS-1 were investigated in detail.

\section{THEORETICAL AND EXPERIMENTAL METHOD}

\section{The first-principles calculations}

The Vienna ab-Initio Simulation Package (VASP) [24,25] was used to perform first-principles calculations based on density functional theory (DFT) with projectedaugmented-waves pseudopotential method within generalized-gradient approximation $[26,27]$. The most stable crystal structures of the starting materials including Mo, $\mathrm{Nb}, \mathrm{Ta}, \mathrm{V}, \mathrm{Si}, \mathrm{Al}$ from the Materials Project Database [28] were used as input for full optimization with DFT and the corresponding space groups are listed in Table 1. For the individual metal disilicides, such as $\mathrm{MoSi}_{2}, \mathrm{NbSi}_{2}, \mathrm{TaSi}_{2}$, and $\mathrm{VSi}_{2}$, they all had the hexagonal C40 crystal structure with the space group of $\mathrm{PG}_{2} 22$ from the Materials Project Database, but only $\mathrm{NbSi}_{2}$ and $\mathrm{TaSi}_{2}$ crystal structures with this space group were the most stable [28]. Meanwhile, Gild et al. [20] reported that a high-entropy silicide, namely $\left(\mathrm{Mo}_{0.2} \mathrm{Nb}_{0.2} \mathrm{Ta}_{0.2} \mathrm{Ti}_{0.2} \mathrm{~W}_{0.2}\right) \mathrm{Si}_{2}$, possessed the aforementioned hexagonal $\mathrm{C} 40$ crystal structure. In this case, we assumed that the individual metal disilicides, aluminosilicides and high-entropy alumino-silicides all possessed the similar crystal structures with the space group of $P 6_{2} 22$, as shown in Fig. 1. Here Fig. $1 \mathrm{a}$ and $\mathrm{b}$ are two alternative views of the hexagonal unit cell showing the $\mathrm{ABC}$ stacking sequences. The red balls represent the atoms at the cationic sublattice $(\mathrm{Mo}, \mathrm{Nb}, \mathrm{Ta}$, or $\mathrm{V})$ and the blue balls stand for the atoms at the anionic sublattice (Al or $\mathrm{Si}$ ). To mimic the complete chemical disorder at both cationic and anionic sublattice for individual metal alumino-silicides and HEAS-1, the special quasi-random structure (SQS) approach [29] was adopted to construct the structures. To be specific, the Alloy Theoretic Automated Toolkit code [30] was utilized to generate the SQS with 36 atoms in which 12 atoms resided at the cation positions and the other 24 atoms occupied the anion positions. For the DFT calculations of energies and lattice parameters in this work, the energy cutoff was $600 \mathrm{eV}$ and the $k$-mesh grid was $2 \pi \times 1 / 60 \AA^{-1}$. Meanwhile, the electronic energy convergence criterion was $10^{-6} \mathrm{eV}$ and all structures were relaxed until forces acting on each atom became smaller than $0.01 \mathrm{eV} \AA^{-1}$.

\section{Synthesis of HEAS-1}

The commercially available $\mathrm{Mo}, \mathrm{Nb}, \mathrm{Ta}, \mathrm{V}, \mathrm{Si}$, and $\mathrm{Al}$ powders $(99.9 \%$ purity, average particle size: $1-3 \mu \mathrm{m}$, Shanghai ChaoWei Nanotechnology Co. Ltd., China) were used as starting materials to synthesize HEAS- 1 . The starting powders were mixed with a ratio of $8.33 \mathrm{~mol} \%$ Mo, $8.33 \mathrm{~mol} \% \mathrm{Nb}, \quad 8.33 \mathrm{~mol} \%$ Ta, $8.33 \mathrm{~mol} \% \mathrm{~V}$, $33.33 \mathrm{~mol} \% \mathrm{Si}$, and $33.33 \mathrm{~mol} \% \mathrm{Al}$, and then milled by hand for $1 \mathrm{~h}$ in an agate mortar. Afterwards, they were put into an alumina crucible with an alumina lid and the whole assembly was directly placed inside a horizontal alumina tube furnace. Finally, they were heated from room temperature to $1573 \mathrm{~K}$ at a rate of $10 \mathrm{~K} \mathrm{~min}^{-1}$, held for $30 \mathrm{~min}$, and followed by furnace cooling down naturally to room temperature to obtain HEAS- 1 powders. The whole heating and cooling process was conducted in flowing Argon gas (99.99\%, purity) with a flowing rate of $200 \mathrm{sccm}$.

\section{Characterization}

The phase composition of the as-synthesized powders was first analyzed by X-ray diffraction (XRD) using $\mathrm{Cu}$ $\mathrm{Ka}$ radiation $(0.15418 \mathrm{~nm})$ (X'pert PRO; PANalytical, Netherlands) operated under a voltage of $40 \mathrm{kV}$ and a current of $40 \mathrm{~mA}$. The equivalent counting time for a

Table 1 Calculated equilibrium lattice parameters, space group and DFT energies of the ground-state crystal structures of different elementary substances

\begin{tabular}{ccccccc}
\hline Systems & $\mathrm{Mo}$ & $\mathrm{Nb}$ & $\mathrm{Ta}$ & $\mathrm{V}$ & $\mathrm{Si}$ & $\mathrm{Al}$ \\
\hline Lattice parameters $a(\AA)$ & 3.163 & 3.308 & 3.319 & 2.997 & 5.463 & 4.039 \\
Space group & $\operatorname{Im} \overline{3} m$ & $\operatorname{Im} \overline{3} m$ & $\operatorname{Im} \overline{3} m$ & $\operatorname{Im} \overline{3} m$ & $F d \overline{3} m$ & $F m \overline{3} m$ \\
Energies $E\left(\mathrm{eV} \mathrm{atom}{ }^{-1}\right)$ & -10.935 & -10.216 & -11.814 & -8.992 & -5.424 & -3.747 \\
\hline
\end{tabular}




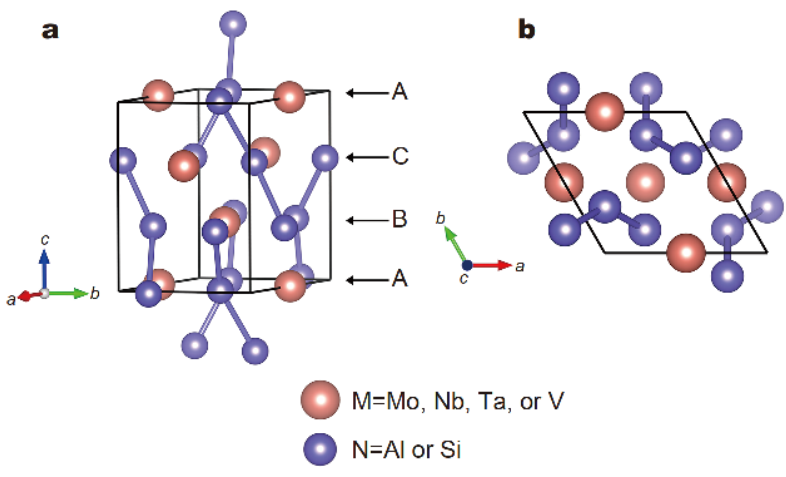

Figure 1 A simple schematic illustration of the atomic structure that does not take the lattice distortion into account of HEAS-1. (a) and (b) are two alternative views of the hexagonal unit cell showing the $\mathrm{ABC}$ stacking sequences.

conventional point detector would be $30 \mathrm{~s}$ per point at $0.01^{\circ} 2 \theta$ increments. The morphology, microstructure and compositional uniformity of the as-synthesized products were then characterized by scanning electron microscope (SEM, Supra-55; Zeiss, Germany) and transmission electron microscope (TEM, Tecnai F30G2; FEI, Netherlands) equipped with energy dispersive spectroscopy (EDS). In particular, for TEM characterizations, $2 \mathrm{~g}$ powders were dissolved into ethanol, exposed to ultrasound for $10 \mathrm{~min}$ and then the clear liquid solution on the surface was dropped on the copper screen with carbon film by pipette.

\section{RESULTS AND DISCUSSION}

In order to analyze the synthesis possibility of HEAS-1, the lattice size difference, $\delta$, an empirical parameter to predict the formation possibility of high-entropy materials $[14,16]$, should be first analyzed. The $\delta$ of HEAS- 1 can be calculated by the following equation:

$\delta=\sqrt{\sum_{i=1}^{n} \frac{n_{i}}{2}\left[\left(1-\frac{a_{i}}{\bar{a}}\right)^{2}+\left(1-\frac{c_{i}}{\bar{c}}\right)^{2}\right]}$, where $n$ is the metal alumino-silicides component species in the HEAS- $1, n_{i}$ is the molar fraction of the ith individual metal alumino-silicides of HEAS- $1, a_{i}$ and $c_{i}$ are the corresponding lattice parameters, and $\bar{a}=\sum_{i=1}^{n} n_{i} a_{i}$ and $\bar{c}=\sum_{i=1}^{n} n_{i} c_{i}$ are the averaged lattice parameters. In general, the smaller $\delta$ suggests the smaller lattice distortion and finally results in the higher formation possibility of the system. In this case, the calculated $\delta$ of HEAS- 1 by using the lattice parameters in Table 2 is $1.893 \%$, which is smaller than that of the reported high-entropy $\left(\mathrm{Zr}_{0.25} \mathrm{Ta}_{0.25} \mathrm{Nb}_{0.25} \mathrm{Ti}_{0.25}\right) \mathrm{C}$ carbides (2.959\%) [16] and $\left(\mathrm{Hf}_{0.2} \mathrm{Zr}_{0.2} \mathrm{Ta}_{0.2} \mathrm{Nb}_{0.2} \mathrm{Ti}_{0.2}\right) \mathrm{B}_{2}$ diborides (2.648\%) [19]. This result suggests that HEAS- 1 can be synthesized from the aspect of lattice size difference. What's more, the thermodynamics of the possible chemical reactions during HEAS- 1 synthesis process should be analyzed in detail. In the current work, the starting materials are composed of $\mathrm{Mo}, \mathrm{Nb}, \mathrm{Ta}, \mathrm{V}, \mathrm{Si}$, and $\mathrm{Al}$ powders. As a result, the relationship between the standard Gibbs free energy $\left(\Delta G_{R, T}^{\theta}\right)$ of the possible chemical reactions and temperature $(T)$ can be described as follows:

$$
\begin{aligned}
& \mathrm{Mo}+\mathrm{Si}+\mathrm{Al} \rightarrow \mathrm{Mo}\left(\mathrm{Al}_{0.5} \mathrm{Si}_{0.5}\right)_{2} \\
& \Delta G_{R, T}^{\theta}=\Delta G_{\text {mix }}^{(2)} ; \\
& \mathrm{Nb}+\mathrm{Si}+\mathrm{Al} \rightarrow \mathrm{Nb}\left(\mathrm{Al}_{0.5} \mathrm{Si}_{0.5}\right)_{2} \\
& \Delta G_{R, T}^{\theta}=\Delta G_{\text {mix }}^{(3)} \\
& \mathrm{Ta}+\mathrm{Si}+\mathrm{Al} \rightarrow \mathrm{Ta}\left(\mathrm{Al}_{0.5} \mathrm{Si}_{0.5}\right)_{2} \\
& \Delta G_{R, T}^{\theta}=\Delta G_{\text {mix }}^{(4)} ; \\
& \mathrm{V}+\mathrm{Si}+\mathrm{Al} \rightarrow \mathrm{V}\left(\mathrm{Al}_{0.5} \mathrm{Si}_{0.5}\right)_{2} \\
& \Delta G_{R, T}^{\theta}=\Delta G_{\text {mix }}^{(5)}
\end{aligned}
$$

Table 2 Calculated equilibrium lattice parameters, DFT energies, mixing enthalpy, mixing entropy, and the lattice size difference of the generated HEAS- 1 and four individual metal alumino-silicides at $0 \mathrm{~K}$ and $0 \mathrm{~Pa}$ by chemical reaction $(n)$

\begin{tabular}{cccccc}
\hline System & HEAS-1 & $\mathrm{Mo}\left(\mathrm{Al}_{0.5} \mathrm{Si}_{0.5}\right)_{2}$ & $\mathrm{Nb}\left(\mathrm{Al}_{0.5} \mathrm{Si}_{0.5}\right)_{2}$ & $\mathrm{Ta}_{\left(\mathrm{Al}_{0.5} \mathrm{Si}_{0.5}\right)_{2}}$ & $\mathrm{~V}\left(\mathrm{Al}_{0.5} \mathrm{Si}_{0.5}\right)_{2}$ \\
\hline Lattice parameter $a(\AA)$ & 4.811 & 4.711 & 4.926 & 4.919 & 4.692 \\
Lattice parameter $c(\AA)$ & 6.703 & 6.749 & 6.770 & 6.748 & 6.545 \\
Energies $E\left(\mathrm{eV} \mathrm{atom}{ }^{-1}\right)$ & -6.888 & -7.082 & -6.848 & -7.321 & -6.368 \\
Mixing enthalpy $\Delta H_{\text {mix }}^{(n)}\left(\mathrm{kJ} \mathrm{mol}^{-1}\right)$ & $1.616(n=6)-32.285(n=7)$ & $-36.664(n=2)$ & $-37.221(n=3)$ & $-31.454(n=4)$ & $-30.264(n=5)$ \\
Mixing entropy $\Delta S_{\text {mix }}^{(n)}$ & $0.462 R(n=6) 0.924 R(n=7)$ & $0.462 R(n=2)$ & $0.462 R(n=3)$ & $0.462 R(n=4)$ & $0.462 R(n=5)$ \\
Lattice size difference $\delta(\%)$ & 1.893 & N/A & N/A & N/A & N/A \\
\hline
\end{tabular}




$$
\begin{aligned}
& \frac{1}{4} \mathrm{Mo}\left(\mathrm{Al}_{0.5} \mathrm{Si}_{0.5}\right)_{2}+\frac{1}{4} \mathrm{Nb}\left(\mathrm{Al}_{0.5} \mathrm{Si}_{0.5}\right)_{2} \\
& \quad+\frac{1}{4} \mathrm{Ta}\left(\mathrm{Al}_{0.5} \mathrm{Si}_{0.5}\right)_{2}+\frac{1}{4} \mathrm{~V}\left(\mathrm{Al}_{0.5} \mathrm{Si}_{0.5}\right)_{2} \\
& \rightarrow\left(\mathrm{Mo}_{0.25} \mathrm{Nb}_{0.25} \mathrm{Ta}_{0.25} \mathrm{~V}_{0.25}\right)\left(\mathrm{Al}_{0.5} \mathrm{Si}_{0.5}\right)_{2} \\
& \Delta G_{R, T}^{\theta}=\Delta G_{\text {mix }}^{(6)} \\
& \frac{1}{4} \mathrm{Mo}+\frac{1}{4} \mathrm{Nb}+\frac{1}{4} \mathrm{Ta}+\frac{1}{4} \mathrm{~V}+\mathrm{Si}+\mathrm{Al} \\
& \rightarrow\left(\mathrm{Mo}_{0.25} \mathrm{Nb}_{0.25} \mathrm{Ta}_{0.25} \mathrm{~V}_{0.25}\right)\left(\mathrm{Al}_{0.5} \mathrm{Si}_{0.5}\right)_{2} \\
& \Delta G_{R, T}^{\ominus}=\Delta G_{\text {mix }}^{(7)},
\end{aligned}
$$

where $\Delta G_{\text {mix }}^{(n)}$ is the mixing Gibbs free energy of the chemical reaction $(n)$ and can be calculated by the following equation:

$\Delta G_{\text {mix }}^{(n)}=\Delta H_{\text {mix }}^{(n)}-T \Delta S_{\text {mix }}^{(n)}$,

where $\Delta H_{\text {mix }}^{(n)}$ and $\Delta S_{\text {mix }}^{(n)}$ are the calculated mixing enthalpy and mixing entropy of the generated HEAS- 1 and four individual metal alumino-silicides by chemical reaction (n), respectively. $\Delta H_{\text {mix }}^{(n)}$ can be approximated by its value at $0 \mathrm{~K}\left(\Delta H_{\text {mix }}^{0 \mathrm{~K}(n)}\right)$ which can be calculated by the following equation based on the DFT energies:

$\Delta H_{\text {mix }}^{0 \mathrm{~K}(n)}=E_{\text {pro }}-\bar{E}_{\text {pre }}$,

where $E_{\text {pro }}$ represents the ground-state DFT energies of the products, and $\bar{E}_{\text {pre }}$ stands for the averaged groundstate DFT energies of the reactants. The equilibrium lattice parameters and DFT energies of the elementary substances and metal alumino-silicides including HEAS-1 are listed in Tables 1 and 2, respectively. By using the corresponding DFT energies, the $\Delta H_{\text {mix }}^{0 \mathrm{~K}(n)}(n=2,3,4,5,6$, 7) can be calculated and the results are listed in Table 2 . In particular, the $\Delta H_{\text {mix }}^{0 \mathrm{~K}(n)}$ of Reaction (6) is larger than zero, suggesting that HEAS- 1 is thermodynamically unstable with respect to the four individual metal aluminosilicides at $0 \mathrm{~K}$ and $0 \mathrm{~Pa}$. However, the effect of $\Delta S_{\text {mix }}^{(n)}$ on the thermodynamic stability of the system should also be considered. The calculated $\Delta S_{\text {mix }}^{(n)}$ of the generated HEAS1 and four individual metal alumino-silicides by chemical reaction $(n)$ can be expressed as:

$\Delta S_{\text {mix }}^{(n)}=\Delta S_{\text {mix }}^{\text {pro }}-\Delta \bar{S}_{\text {mix }}^{\text {pre }}$

where $\Delta S_{\text {mix }}^{\text {pro }}$ is the mixing entropy of the products and $\Delta S_{\text {mix }}^{\text {pre }}$ is the averaged mixing entropy of the reactants. In addition, the mixing entropy $\Delta S_{\text {mix }}$ for a compound can be expressed as follows [14]:

$$
\begin{aligned}
\Delta S_{\text {mix }}= & -R\left\{\frac{X}{X+Y} \sum_{i=1}^{N_{h}} x_{i}^{h} \ln \left(x_{i}{ }^{h}\right)\right. \\
& \left.+\frac{Y}{X+Y} \sum_{i=1}^{N_{k}} x_{i}{ }^{k} \ln \left(x_{i}{ }^{k}\right)\right\},
\end{aligned}
$$

where $R$ is the gas constant, $X$ and $Y$ represent the number of sites in the sublattice $h$ and $k$, respectively, $N_{h}$ and $N_{k}$ are the elements species in the sublattice $h$ and $k$, respectively, and $x_{i}^{h}$ and $x_{i}^{k}$ are the molar fractions of the constituent $i$ in the sublattice $h$ and $k$, respectively. As a result, the calculated $\Delta S_{\text {mix }}^{(n)}$ values of the generated HEAS1 and four individual metal alumino-silicides by Reaction (n) are listed in Table 2. In this case, the thermodynamics analysis results of the possible Reactions (2)-(7) are displayed in Fig. 2a, from which it can be clearly observed that all the reactions can proceed simultaneously above $1000 \mathrm{~K}$ because the $\Delta G_{R, T}^{\ominus}$ of all the reactions are less than zero. However, the driving force of Reaction (6) is the smallest among all the reactions, which indicates that it is the most difficult one to occur when competing with

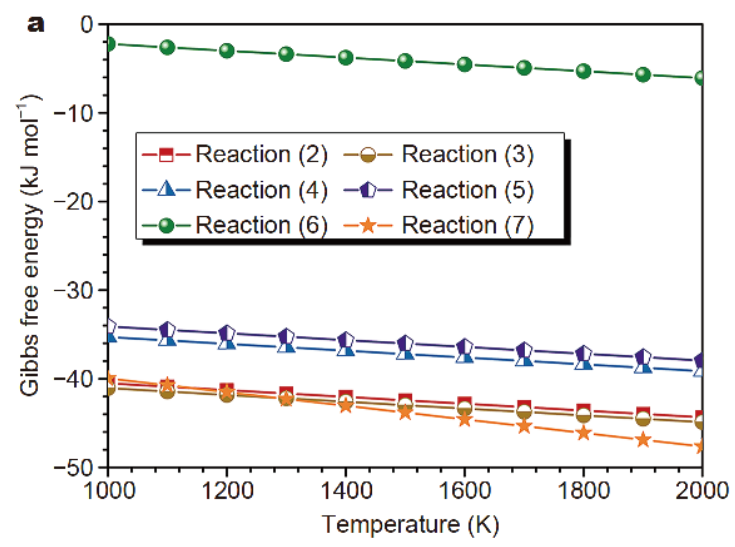

b

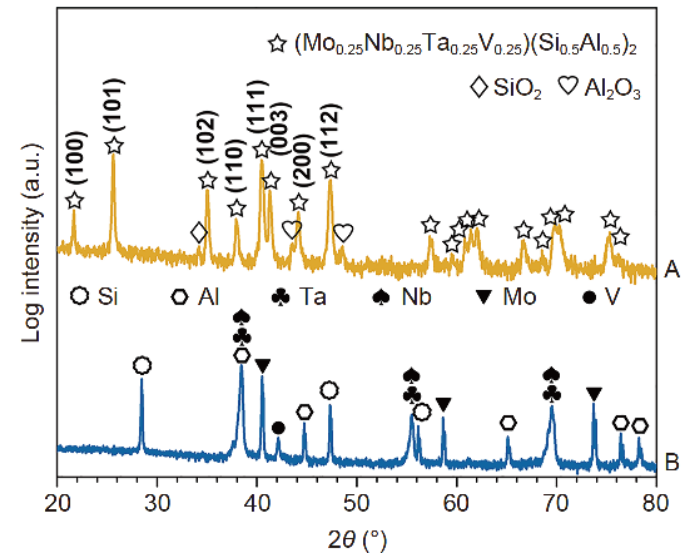

Figure 2 (a) Thermodynamics analysis of the possible chemical reactions during HEAS-1 synthesis process; (b) XRD patterns: A is for the as-synthesized product and $\mathrm{B}$ is for the mixture of the starting materials. 
other reactions. In addition, it should be noted that the $\Delta G_{R, T}^{\theta}$ of all the reactions show a decrease trend with the increase of the temperature. When the temperature is above $1300 \mathrm{~K}$, Reaction (7) is the most prone to occurring due to its largest driving force among all the reactions. In this case, the synthesis of HEAS-1 through Reaction (7) is very probable from the aspect of thermodynamics. Therefore, in combination of lattice size difference and thermodynamics analysis, the fabrication of HEAS-1 is very probable and worthy to being tried in experiments.

Encouraged by the above comprehensive theoretical analyses, the aforementioned experiment was further performed to attempt to fabricate HEAS-1. Fig. $2 b$ shows the XRD patterns of the mixture of the starting materials (B) and the as-synthesized products (A) on a logarithmic scale. It can be found that a single hexagonal phase of metal alumino-silicides can be clearly seen except for the existence of a small amount of $\mathrm{SiO}_{2}$ and $\mathrm{Al}_{2} \mathrm{O}_{3}$ phases. This suggests that HEAS- 1 are successfully synthesized at $1573 \mathrm{~K}$.

To further investigate the morphology, microstructure and compositional uniformity of the as-synthesized HEAS-1, the SEM and TEM characterizations were carried out. Fig. 3a is the typical SEM image of the as-synthesized HEAS-1. It can be obviously observed that the as-synthesized HEAS-1 powders involve numerous irregular particles with the particle sizes of $0.5-3 \mu \mathrm{m}$. Fig. $3 \mathrm{~b}$, $c$ shows the representative bright-field TEM image and the corresponding selected area electron diffraction (SAED) pattern along zone axis [100] of the as-synthesized HEAS-1, respectively. It can be clearly found that the as-synthesized HEAS- 1 exhibit the single-crystal hexagonal structure of metal alumino-silicides because the diffraction spots are arranged in a good symmetry. Fig. $3 \mathrm{~d}$ is the high-resolution TEM (HRTEM) image, from which we can observe a periodic structure with two sets of fringes with the $d$-space of about 0.432 and $0.342 \mathrm{~nm}$ corresponding to $\{100\}$ and $\{101\}$ planes of $\left(\mathrm{Mo}_{0.25} \mathrm{Nb}_{0.25} \mathrm{Ta}_{0.25} \mathrm{~V}_{0.25}\right)\left(\mathrm{Al}_{0.5} \mathrm{Si}_{0.5}\right)_{2}$ phase, respectively. These are in good agreement with the results (0.417 and $0.354 \mathrm{~nm}$ ) from first-principles calculations. Moreover, it should be noted that there is an amorphous layer of 2-4 $\mathrm{nm}$ on the particle surface, which may be due to the presence of amorphous $\mathrm{SiO}_{2}$. To analyze the element compositions of the as-synthesized HEAS-1, the atomic percentages (at\%) of different elements were summarized as follows: Mo (9.35), Nb (10.91), Ta (10.16), V (9.93), Si (29.4), Al (25.69), O (4.56). Clearly, the atomic percentages of $\mathrm{Mo}, \mathrm{Nb}, \mathrm{Ta}$ and $\mathrm{V}$ elements in the cationic site are nearly the same and simultaneously the atomic ratio of the cation elements ( $\mathrm{Mo}, \mathrm{Nb}, \mathrm{Ta}$ and $\mathrm{V}$ ) to the anion elements $(\mathrm{Al}$ and $\mathrm{Si}$ ) is around 1:2. Furthermore, the atomic percentage of Si element is much higher than that of $\mathrm{Al}$ element, which results from the presence of the higher fraction of $\mathrm{Al}_{2} \mathrm{O}_{3}$ than that of $\mathrm{SiO}_{2}$ in the assynthesized HEAS-1 (Fig. 2b). Meanwhile, the presence of oxygen element may come from $\mathrm{Al}_{2} \mathrm{O}_{3}$ and $\mathrm{SiO}_{2}$ in the assynthesized HEAS-1. To investigate the composition uniformity of the as-synthesized HEAS-1, the scanning TEM (STEM)-EDS analysis was further carried out at a collection time of $230 \mathrm{~s}$ and an acceleration voltage of $200 \mathrm{kV}$ and the results are displayed in Fig. 3e. The distribution of all elements, including $\mathrm{Mo}, \mathrm{Nb}, \mathrm{Ta}, \mathrm{V}, \mathrm{Si}$ and $\mathrm{Al}$, is very uniform without evident localization or segregation. In combination with the results from XRD, SEM, and TEM analyses, the HEAS-1 have been successfully synthesized at $1573 \mathrm{~K}$.

\section{CONCLUSION}

In conclusion, a new class of HECs, namely HEAS-1 with multi-cationic and -anionic structure, was reported for the first time. We first theoretically demonstrated the
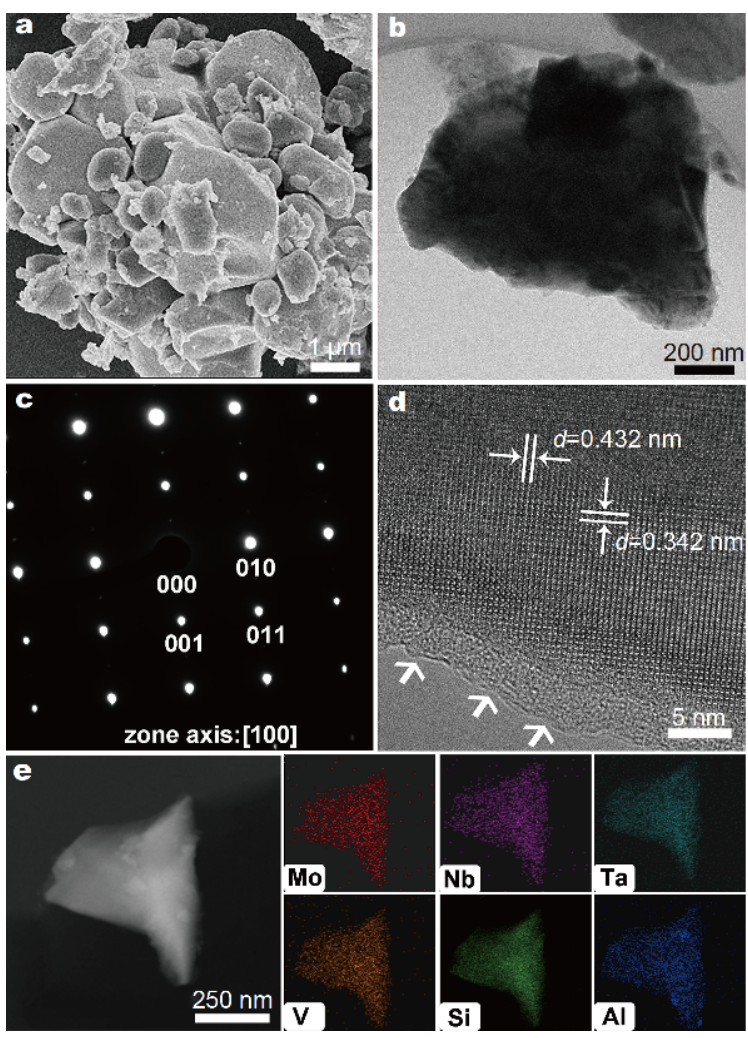

Figure 3 SEM and TEM analysis of the as-synthesized HEAS-1. (a) SEM image; (b) TEM image; (c) SAED pattern; (d) HRTEM image; (e) STEM image and corresponding EDS compositional maps. 
formation possibility of HEAS-1 by analyzing lattice size difference and chemical reaction thermodynamics based on first-principles calculations and then successfully fabricated HEAS- 1 by solid-state reaction at $1573 \mathrm{~K}$ for the first time. The as-synthesized HEAS-1 exhibited the single-crystal hexagonal C40 crystal structure with the space group of $\mathrm{P6}_{2} 22$. More importantly, the distribution of all elements including the cation elements $(\mathrm{Mo}, \mathrm{Nb}, \mathrm{Ta}$ and $\mathrm{V}$ ) and the anion elements ( $\mathrm{Al}$ and $\mathrm{Si}$ ) is highly uniform without evident localization or segregation in the as-synthesized HEAS-1.

\section{Received 13 July 2019; accepted 14 August 2019;} published online 19 September 2019

1 Miracle DB, Senkov ON. A critical review of high entropy alloys and related concepts. Acta Mater, 2017, 122: 448-511

2 Tsai MH, Yeh JW. High-entropy alloys: a critical review. Mater Res Lett, 2014, 2: 107-123

3 Zhang W, Liaw PK, Zhang Y. Science and technology in highentropy alloys. Sci China Mater, 2018, 61: 2-22

4 Shi $\mathrm{P}$, Ren W, Zheng T, et al. Enhanced strength-ductility synergy in ultrafine-grained eutectic high-entropy alloys by inheriting microstructural lamellae. Nat Commun, 2019, 10: 489

5 El-Atwani $\mathrm{O}, \mathrm{Li} \mathrm{N}, \mathrm{Li} \mathrm{M}$, et al. Outstanding radiation resistance of tungsten-based high-entropy alloys. Sci Adv, 2019, 5: eaav2002

6 Shi Y, Yang B, Xie X, et al. Corrosion of $\mathrm{Al}_{x} \mathrm{CoCrFeNi}$ highentropy alloys: Al-content and potential scan-rate dependent pitting behavior. Corros Sci, 2017, 119: 33-45

7 Zhang ZJ, Mao MM, Wang J, et al. Nanoscale origins of the damage tolerance of the high-entropy alloy $\mathrm{CrMnFeCoNi}$. Nat Commun, 2015, 6: 10143

8 Chen S, Li W, Xie X, et al. Nanoscale serration and creep characteristics of $\mathrm{Al}_{0.5} \mathrm{CoCrCuFeNi}$ high-entropy alloys. J Alloys Compd, 2018, 752: 464-475

9 Niu S, Kou H, Zhang $\mathrm{Y}$, et al. The characteristics of serration in $\mathrm{Al}_{0.5} \mathrm{CoCrFeNi}$ high entropy alloy. Mater Sci Eng-A, 2017, 702: 96103

10 Rost CM, Sachet E, Borman T, et al. Entropy-stabilized oxides. Nat Commun, 2015, 6: 8485

11 Jiang $\mathrm{S}, \mathrm{Hu} \mathrm{T}$, Gild J, et al. A new class of high-entropy perovskite oxides. Scripta Mater, 2018, 142: 116-120

12 Harrington TJ, Gild J, Sarker P, et al. Phase stability and mechanical properties of novel high entropy transition metal carbides. Acta Mater, 2019, 166: 271-280

13 Ye B, Wen T, Huang K, et al. First-principles study, fabrication, and characterization of $\left(\mathrm{Hf}_{0.2} \mathrm{Zr}_{0.2} \mathrm{Ta}_{0.2} \mathrm{Nb}_{0.2} \mathrm{Ti}_{0.2}\right) \mathrm{C}$ high-entropy ceramic. J Am Ceram Soc, 2019, 102: 4344-4352

14 Ye B, Wen T, Nguyen MC, et al. First-principles study, fabrication and characterization of $\left(\mathrm{Zr}_{0.25} \mathrm{Nb}_{0.25} \mathrm{Ti}_{0.25} \mathrm{~V}_{0.25}\right) \mathrm{C}$ high-entropy ceramics. Acta Mater, 2019, 170: 15-23

15 Feng L, Fahrenholtz WG, Hilmas GE, et al. Synthesis of singlephase high-entropy carbide powders. Scripta Mater, 2019, 162: 90-
93

16 Ye B, Ning S, Liu D, et al. One-step synthesis of coral-like highentropy metal carbide powders. J Am Ceram Soc, 2019, 102: 63726378

17 Gild J, Zhang Y, Harrington T, et al. High-entropy metal diborides: a new class of high-entropy materials and a new type of ultrahigh temperature ceramics. Sci Rep, 2016, 6: 37946

18 Tallarita G, Licheri R, Garroni S, et al. Novel processing route for the fabrication of bulk high-entropy metal diborides. Scripta Mater, 2019, 158: 100-104

19 Liu D, Wen T, Ye B, et al. Synthesis of superfine high-entropy metal diboride powders. Scripta Mater, 2019, 167: 110-114

20 Gild J, Braun J, Kaufmann K, et al. A high-entropy silicide: $\left(\mathrm{Mo}_{0.2} \mathrm{Nb}_{0.2} \mathrm{Ta}_{0.2} \mathrm{Ti}_{0.2} \mathrm{~W}_{0.2}\right) \mathrm{Si}_{2}$. J Materiomics, 2019, doi: 10.1016/j. jmat.2019.03.002

21 Qin Y, Liu JX, Li F, et al. A high entropy silicide by reactive spark plasma sintering. J Adv Ceram, 2019, 8: 148-152

22 Ye B, Wen $\mathrm{T}$, Liu $\mathrm{D}$, et al. Oxidation behavior of $\left(\mathrm{Hf}_{0.2} \mathrm{Zr}_{0.2} \mathrm{Ta}_{0.2^{-}}\right.$ $\mathrm{Nb}_{0.2} \mathrm{Ti}_{0.2}$ ) C high-entropy ceramics at $1073-1473 \mathrm{~K}$ in air. Corros Sci, 2019, 153: 327-332

23 Ye B, Wen T, Chu Y. High-temperature oxidation behavior of $\left(\mathrm{Hf}_{0.2} \mathrm{Zr}_{0.2} \mathrm{Ta}_{0.2} \mathrm{Nb}_{0.2} \mathrm{Ti}_{0.2}\right) \mathrm{C}$ high-entropy ceramics in air. $\mathrm{J} \mathrm{Am}$ Ceram Soc, 2019, 122: jace.16725

24 Kresse G, Furthmüller J. Efficient iterative schemes for ab initio total-energy calculations using a plane-wave basis set. Phys Rev B, 1996, 54: 11169-11186

25 Kresse G, Hafner J. Ab initio molecular dynamics for liquid metals. Phys Rev B, 1993, 47: 558-561

26 Blöchl PE. Projector augmented-wave method. Phys Rev B, 1994, 50: $17953-17979$

27 Perdew JP, Burke K, Ernzerhof M. Generalized gradient approximation made simple. Phys Rev Lett, 1996, 77: 3865-3868

28 Jain A, Ong SP, Hautier G, et al. Commentary: the materials project: a materials genome approach to accelerating materials innovation. APL Mater, 2013, 1: 011002

29 Zunger A, Wei SH, Ferreira LG, et al. Special quasirandom structures. Phys Rev Lett, 1990, 65: 353-356

30 van de Walle A. Multicomponent multisublattice alloys, nonconfigurational entropy and other additions to the alloy theoretic automated toolkit. Calphad, 2009, 33: 266-278

Acknowledgements This work was supported by the National Key Research and Development Program of China (2017YFB0703200), Young Elite Scientists Sponsorship Program by China Association for Science and Technology (2017QNRC001), and the National Natural Science Foundation of China (51802100 and 51972116).

Author contributions Chu Y conceived and designed the experiments. Chu Y and Liu H performed the experiments. Chu Y, Wen T, Liu $\mathrm{H}$, Ye B and Liu D analyzed the data. Wen T performed the firstprinciples calculations. All authors commented on the manuscript.

Conflict of interest The authors declare that they have no conflict of interest. 


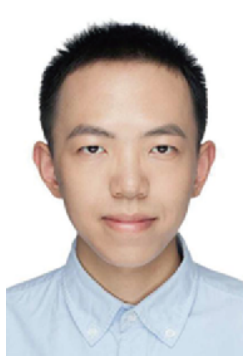

Tongqi Wen is currently a $\mathrm{PhD}$ student at Northwestern Polytechnical University and jointly supervised in Ames laboratory, USA and South China University of Technology. His research interests include computational modeling, crystal structure prediction and materials discovery.

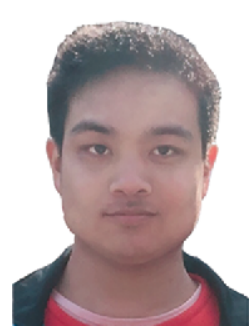

Honghua Liu is currently a Master student at South China University of Technology. His research focuses on the fabrication and characterization of high-entropy ceramics and related powders.

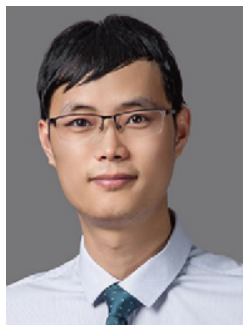

Yanhui Chu is as an associate professor at South China University of Technology. He received his $\mathrm{PhD}$ degree in materials science from Northwestern Polytechnical University in 2016. From January 2014 to August 2015, he was a visiting scholar at Harvard University. His current research interests include high-temperature coatings, high-entropy ceramics and related nanomaterials.

\section{高熵硅铝化物: 一类新型的高熵陶瓷材料}

文通其 ${ }^{1,2 \dagger}$, 刘红华 ${ }^{1 \dagger}$, 叶贝琳 ${ }^{1}$, 刘达 ${ }^{1}$, 褚衍辉 ${ }^{1 *}$

摘要 高熵陶瓷材料因具有巨大的组分空间、独特的微观结构以 及可调控的性能而引起国内外研究者的广泛关注. 目前, 高熵陶瓷 材料的研究主要集中在具有多主元阳离子结构的高摘陶瓷材料领 域. 然而, 关于具有多主元阴阳离子结构的高熵陶瓷材料的研究报 道较少. 本文首次报道了一类新型的具有多主元阴阳离子结构的高 熵陶瓷材料, 即高熵硅铝化物 $\left(\mathrm{Mo}_{0.25} \mathrm{Nb}_{0.25} \mathrm{Ta}_{0.25} \mathrm{~V}_{0.25}\right)\left(\mathrm{Al}_{0.5} \mathrm{Si}_{0.5}\right)_{2}$. 首先 基于第一性原理计算从化学反应热力学和晶格尺寸差异两个方面 分析了高熵硅铝化物形成的可能性, 然后以过渡金属粉体以及硅 粉和铝粉为原料, 采用固相反应技术在 $1573 \mathrm{~K}$ 下成功地制备出等 摩尔比的高熵硅铝化物. 研究结果表明: 所制备的高熵硅铝化物具 有单一金属硅铝化物的六方晶系晶体结构, 同时, 所有组成元素的 分布具有高度均匀性. 该研究不仅丰富了高熵陶瓷材料的种类, 而 且为开拓具有多主元阴阳离子结构的高熵陶瓷材料提供了参考。 